\title{
Conceptual Ideas About the Creative Elite as a Creator of Creative Social Space
}

\author{
Stoyanova Linda Leonidovna \\ post-graduate student of the department of philosophy, sociology and socio- \\ cultural management of State institution "South Ukrainian National \\ Pedagogical University of. K. D. Ushinsky"
}

\begin{abstract}
This study reveals the idea that the socially multivariant processes of the present cause interest in the creative elite, who are constantly searching for new patterns and landmarks, which can be the basis for the development of all structures of society as a whole. The article discusses the main theoretical and methodological approaches to the study of your elite. It is determined that the existence of various methodologies for the study of the creative elite requires a socio-philosophical view of the architectonics of spiritual production, which also makes it necessary to integrate the theoretical and methodological principles into the conceptual whole of the research. It is revealed that the need is a conceptual understanding of the creative elite, which also serves as the basis for the formation and formation of a special creative social space.

It is especially emphasized that it is possible to make up ideas about the creative elite as a special social space on the basis of narrativ as an interdisciplinary methodological construct in the modern social sciences. From the given methodological foundations, the idea of interpreting consciousness as a set of texts, recognizing the possibility of multiple interpretations of each text, and the vision of society and culture as a unity of blurred, decentralized structures in postmodernism are highlighted. The conclusion is that it is possible to consider the creative elite as the bearer of a set of certain social, ethical, psychological, spiritual connections and relationships. The functional characteristics of the representatives of elites are the organizing force that makes any society a coherent sociocultural system. Dynamic creative associations and organizations involve wide public circles in the process of creating new values and actualize their inner potential, from which a new cultural layer is born - a space of positive self-realization of the individual.
\end{abstract}

Keywords: elite, creativity, creative elite, phenomenon, narrative, social space.

Introduction. The social multivariate processes of the present arouse interest in the creative elite, leading a constant search for new designs and landmarks that can be the basis for the development of all structures of society as a whole. The priority of social technologies requires a continuous social and philosophical understanding of the architectonics of social and spatial arrangement, which makes it necessary to integrate disparate theoretical achievements in the study of elites into a single space of social and philosophical research.

Despite a wide range of research works in the field of cultural policy, spirituality and elitism, synthesizing various data and building the concept of creative possibilities and effective activities of the creative elite. 
The degree of elaboration of the problem. Various studies have revealed questions concerning the influence of the elite on social processes. The analysis of the phenomenon of the elite as a creative active minority in the context of the development of culture and civilization is made in the works of O. Shpengler, A. Toynbee. An important role in the development of understanding of the creative elite also belongs to N.A. Berdyaev and H.Ortega-y-Gasset. The ethical-philosophical and cultural studies of M.M.Bakhtin, V.S.Bibler, M.Veber, A.F.Losev, V.V.Rozanov, essential for understanding the phenomenon of the creative elite in the context of the creative role of culture in the formation of personality are M.S.Kagan, D.S. Likhachev, G.S.Batishchev, Y.Habermas and others. In the works of T. Adorno, S. Bulgakov, G. Markuse, F. Schlegel, M. Horkheimer, the problems of the creative elite are touched upon on the basis of the opposition of "mass" and "elite" art.

In general, it is possible to single out from the works that one of the factors that intensify interest in the study of the creative elite, are the processes leading to the increasing role of the example of the creative elite in modern practice. At the same time, according to Z. R. Valeeva, there are few works that study the phenomenon of the spiritual and creative elite from a social and philosophical point of view. This phenomenon in the framework of the postnon-classical paradigm is also a little studied. The need for this study is due to the use of an interdisciplinary integrated approach to the problem of the activities of the spiritual and creative elite, analyzed from the point of view of social and philosophical discourse. Also, the conditions that are necessary for the transition of the existence and functioning of the spiritual and creative elite to a new level corresponding to the post-industrial level of development of modern society turned out to be insufficiently studied [1].

Insufficiently lit parts of the problem. The need is a conceptual understanding of the creative elite, which also serves as the basis for the formation and formation of a special creative social space.

The purpose of the study is to reveal the conceptual ideas about the creative elite and to identify its main functional characteristics. To determine the possibilities of the creative elite in building a creative social space.

The main content (research methodology). In the study of the creative elite, the theoretical and methodological basis was the combination of a number of scientific 
approaches. He was composed of the fundamental ideas of structural and functional analysis, existentialism, philosophical anthropology, social psychology, theory of communicative action. It is highlighted that the socio-philosophical analysis of the phenomenon of the creative elite demonstrates the connection of this phenomenon with the idea of spiritual perfection; The phenomenon of the creative elite should be considered in close connection with the analysis of the concept of creativity, as well as with the understanding of the personality characteristics of the representative of the creative elite.

From the position of V. Golik we single out that it is possible to consider the creative elite in a more special social context than was previously done. The theory of elites on the basis of the integration of sciences makes it possible to study the elite, based on the idea of the systematic nature and orderliness of the historically established society, its definite orderliness and evolution [2].

Despite the presence of flaws in the value approach, preference is given to it, rather than to the functional approach, since the personified elite is not a functional mechanism for solving problems, but a historically unique stratum, conscious of its responsibility for producing the ideological and ideological horizons of social development. From the theoretical and methodological foundations of the research by Z. R. Valeeva, we single out a combination of a number of scientific approaches, but at the same time, a synergistic approach is used in studying the functioning of elites in the conditions of a modern transforming community, a phenomenological approach to understanding the slice of modern culture with a heuristic and creative resource manifested in its phenomena, which can be used in the study of innovative space, the interaction of society and the creative elite .. [1].

In our opinion, the existence of various methodologies for the study of the creative elite requires a socio-philosophical view of the architectonics of spiritual production, which also makes it necessary to integrate the theoretical and methodological principles into the conceptual whole of the research. In this regard, it is possible to refer to the works of A. Schütz, who concludes that each researcher receives a model of the social world, or, better to say, its reconstruction ... .., and this model is fully consistent with the postulate of a subjective point of view ....... And this type is designed in such a way as to perform only typical actions, then objective and subjective elements will be combined in the formation of single actions. On the other hand, the formation of a type, the choice of a typical event, as well as 
elements considered as typical, are all conceptual terms that can be objectively discussed and are open to criticism and verification [3, p. 110].

The main content (Discussion). For the formation of ideas about the creative elite as a holistic phenomenon, it becomes necessary to highlight such qualitative characteristics that would be objective, independent of the subjective inclinations and preferences of various researchers. In our study, we draw attention to the following theoretical and methodological foundations, in fact, already traditional and generally accepted, and indicate that it is necessary to synthesize them and build a concept based on the idea of the creative elite as representing a particular social space.

According to P.A. Sorokin, people who belong to the highest stratum in any one respect usually belong to the same stratum in other parameters ... [4]. From the arguments of V. Pareto, it follows that in society, along with the elite, there must always be a "counter-elite" (potential elite) - persons who, by their psychological qualities, could enter the elite, but did not enter through their social status. The change of elites allows you to maintain social equilibrium, because it ensures the coming to power of elites who have the qualities demanded by the social situation $[5$, p. 35].

To highlight the functional characteristics of the creative elite, refer to the following provisions. Thus, according to LK Vasilyeva, the functional characteristics of members of the elite are the organizing force that makes any society an integrated social system, if we consider the signs of integrity, first of all, the presence of any common goals and actions aimed at their achievement [6]. The elite, as a social subject that preserves existing values or forms new ones, ultimately determines the fate of the community to which it belongs [6].

Based on the thought of S. I. Shelonaev, the phenomenon of the creative elite should be considered in close connection with the analysis of the concept of creativity, as well as with the understanding of the personality characteristics of the representative of the creative elite. In this context, the creative elite can be seen as the bearer of a set of certain social, ethical, psychological, spiritual connections and relationships. In the case of the creative elite, its impact on different aspects of society's life occurs in the ideal sphere at a more complex level, and the essence of this impact is determined by the essential "value" characteristics of the creative elite representatives [7]. 
From the study of E. A. Gorchitskaya, we draw attention to the position that associations of elite, intellectuals and intelligentsia are an integral part of the socio-cultural sphere of modern society, both in the capital and in the regions, at the same time being a form of consolidation, an adaptation mechanism of co-optation and social self-organization, characterizing the level of development of civil society [8]. Representatives of the elite, intellectuals, intellectuals for the implementation of effective communication activities actually create around themselves a social interaction space, allowing them to go beyond the usual existence. This space has a positive effect on the state and development of society [8].

In the theoretical and methodological foundations of the research of N. V. Kovalyunas the approaches of classical and modern elitology and, on this basis, the general characteristics of the elite as a social phenomenon are given (as a first approximation), the development of this social phenomenon is traced - the elite in the structure of society both theoretically and and in historical aspects. Methods of comparative analysis, typology, classification and systematization are used to build a social typology of elites and to identify the peculiarities of the socio-philosophical understanding of the processes of social differentiation and stratification, as well as to study theoretical and methodological problems associated with the formation and development of the elite of Russian society. Regarding the technique, it is diverse and largely traditional - these are general scientific methods of cognition (analysis and synthesis, abstraction, induction, deduction, analogy, etc.) [9].

We pay special attention to the views of Z. R. Valeeva in the context of highlighting the socio-philosophical foundations of building the space of subject-subject relations of the elite and society. From the point of view of social and philosophical ontology, the creative elite appears to be the creator of social reality, and at the level of personal being, in the course of its activities, personal self-construction also occurs. The value of having information in this unstable system gives way to a creative ethos and ability to act spontaneously in fundamentally new uncertain conditions. Therefore, the qualities that distinguish the spiritual and creative elite of the industrial and post-industrial eras are the skill of social improvisation, the possession of charisma and the skills of competent self-presentation, creativity and dialogue [1].

From the theory of $\mathrm{P}$. Bourdieu we single out the idea that the creative elite is characterized by "the desire to accumulate knowledge and skills is inseparable from the 
search for recognition and the desire to create a name for oneself." The specificity of the field of cultural production consists in the combination of two components: power and semantic relations .... So, for example, in the field of literature, writes P. Bourdieu, as well as in any other field of cultural production, there is an opposition of "masters", carriers of tradition, representing dominant trends and genres, - to "beginners" working in new, marginal genres and styles [10, p. 131].

The ideas about the creative elite as a special social space can be made on the basis of the Narrativ as an interdisciplinary methodological construct in the modern social sciences. This provision supplemented, according to I. V. Trotsuk, the requirement of a "linguistic turn" to consider research in the field of social, political, psychological and cultural problems as linguistic [11, p. 41 - 48]. In the narrative problematics, the postmodern extremely aggravated the problem of the text, pointing out that it is impossible in principle to unambiguously assess it, and the problem of cognition, noting the indirect relation of textual reality to the outside world that it "displays"; By its vagueness and uncertainty, the postmodern identified the human problem - since many people generate many interpretations, "instead of building a theoretical model using their own language and following the paths of the rules already set, the researcher has to study the social world in its fragmentary state" [14, p. 41 - 48].

From the given methodological foundations, the idea of interpreting consciousness as a set of texts, recognizing the possibility of multiple interpretations of each text, and the vision of society and culture as a unity of blurred, decentralized structures in postmodernism are highlighted.

Thus, based on the appeal to the narrative and the creative ethos, it is possible to single out the following. In the new format of interaction, the power of rigid directives of the elite is abolished. The traditional "direct" interaction of society and its elite is replaced by indirect. The world of the everyday culture of the majority (its modern myths, images, texts) "slides" along the edge of the topos of elite culture, including values and models of high art.

Building a social space in which the mutual interests of the spiritual and creative elite and society would be realized in a new way, according to Z. R. Valeeva, implies the creation of conditions for the voluntary involvement of representatives of society in the processes of creative and intellectual self-realization, as well as the self-improvement of elite representatives not only in connection with his immediate professional activities, but also in 
the course of joint creative activities with representatives of society. The main driving force behind the development of space are public initiatives that are not artificially introduced "from above", but arise in the depths of public life. The construction of the innovation space is based on the following principles: the unity of the diversity of cultural development, implying an active public circulation of creative ideas; dialogue of cultures and civilization communities; development of information and communication structures and the use of the interactive potential of the subjects of intercultural dialogue, making any national culture more open and capable of self-preservation and development at a new level .... According to Z. R. Valeyeva, the conceptual foundations of building an innovative model of interaction between the spiritual and creative elite and society are : rejection of elitist decision-making and activity manifestations, appeal to anonymity and intuition to encourage public associations and tdelnyh individuals to exercise socially significant initiatives; taking into account the pluralism of the modern world, which includes many criteria of stratification (ethnicity, denomination, age, professional status, education, personal preferences, political views, etc.) [1].

Based on the ideas of Z. R. Valeeva, P. Bourdieu, I. Trotsuk, it is possible to propose and substantiate their Conceptual model of constructing a creative social space with the amendment that the influence of the creative elite on different aspects of society's life occurs in an ideal sphere on a more complex level, and the essence of this impact is determined by the essential "value" characteristics of representatives of the creative elite.

In our opinion, the creative social space, created by the creative elite, necessitates the identification and definition of the logical structure of space (subjects, forms, conceptual bases, results) and its temporal (procedural) side; ideas that the Creative Space Model should be appropriately flexible, dynamic, multi-cultural, variable, which allows the elite to interact with people with different ideological preferences.

Conclusions. On the basis of the analyzed material it is possible to make certain generalizations and conclusions.

It is possible to consider the creative elite as the bearer of a set of certain social, ethical, psychological, spiritual connections and relationships. 
Without a creative elite, neither the flourishing of culture nor education is possible, the position and quality potential of the creative elite are connected with the issues of national identity, the quality of communication, the moral and spiritual atmosphere in society itself.

The functional characteristics of the representatives of elites are the organizing force that makes any society a coherent sociocultural system.

The creative elite acts as an independent objectively existing phenomenon of social existence, which plays an important role in the life of society, has a diverse impact on both the spiritual and other components of the life of the elite and society as a whole, and therefore has the opportunity to be in the construction of a creative social space.

Dynamic creative associations and organizations involve wide public circles in the process of creating new values and actualize their inner potential, from which a new cultural layer is born - a space of positive self-realization of the individual.

Prospects for further research. As a prospect for further research of the creative elite within the framework of the general theoretical orientation of the creative elite, one can cite an analysis of the content and mechanisms of the creative elite influence both on the elite itself in a broader sense and on the society as a whole within the framework of the dichotomy post-industrial and information society.

\section{References}

1. Valeeva, Z. R. (2010) The Transformation of the Relations of the Spiritually - Creative Elite and Society in the Conditions of Modern Modernization Processes: Author. sciences. Specialty HAC 09.00.11 - Social philosophy. Kazan. - 32 p.

2. Golik, N.V. (2002) Ethical in Culture. SPb.: St. Petersburg Philosophical Society. - 256 p.

3. Schütz, A. (2004) Selected: A World that Glows with Meaning: [trans. with him. and Eng.]. M .: Russian Political Encyclopedia (ROSSPEN). - 1056 p. (The Book of Light series.)

4. Sorokin, P. Man. (1992) Civilization. Society. M.

5. Pareto, V. (1969) Elites and circulation. C.S. Heller. Structured social inequality: a reader in comparative social stratification. N.Y. - P.35.

6. Vasilyeva, L. K. (2008) A synergetic approach in the theory of elites and its use in analyzing the political elite (on the example of post-Soviet Russia). M. - 328 p.

7. Shelonaev, S.I. (2005) Ethics of the creative elite: Dissert .. on the list of candidates ... PhD ... Philosophy of Sciences - VAK 09.00.05 Specialty - Ethics. St. Petersburg. $\quad 160$ p.

8. Gorchitskaya, E. A. (2010) Intellectual elite in the cultural and historical development of society. Omsk: IP Sheludivchenko AV, - 128 p. 
9. Kovalyunas, N. V. (2000) Elita in the structure of society: a socio-philosophical analysis: Thesis .. candidate .. philosopher. sciences - specialty VAK: 09.00.11 - social philosophy. Samara. - 200 p.

10. Bourdieu, P. (1996) Social space and the genesis of "classes"// P. Bourdieu. Sociology of politics. M. - P. 55-97.

11. Trotsuk, I.V. (2004) Narrative as an interdisciplinary methodological construct in the modern social// Bulletin of Peoples' Friendship University of Russia. Series: Sociology. - P. $41-48$. 